\title{
A pluralização das fontes de informação política no Brasil: as mídias legislativas
}

\section{Antonio Teixeira de Barros / Cristiane Brum Bernardes}

\section{Resumo:}

A pluralização das mídias no Brasil intensificou-se a partir da década de 1990 com a criação das emissoras de televisão legislativas e a posterior estruturação dos sistemas de comunicação do Parlamento. Esse tipo de jornalismo encontra respaldo no pressuposto de que, assim, o cidadão recebe as notícias diretamente da fonte, sem interveniências externas. Por outro lado, é questionado como modelo de jornalismo e como prática assistencialista e paternalista do Estado, que se apropria de procedimentos e técnicas jornalisticas para formar e influenciar a opinião pública. São esses dilemas que o texto discute, ao mesmo tempo em que apresenta uma síntese histórica sobre a evolução dos veículos institucionais de comunicação do Poder Legislativo brasileiro (Senado Federal e Câmara dos Deputados). O fenômeno da pluralização das fontes resultou no modelo chamado "mídia de fontes", no qual as instituições oferecem o noticiário pronto, a fim de evitar que as notícias institucionais passem pelos filtros e enquadramentos da mídia convencional.

\section{Palavras Chave:}

informação política; informação pública; jornalismo público; representação política.

\begin{abstract}
:
Since the 1990's, a comprehensive communications system has been structured in the Brazilian Congress with the creation of television channels, radio stations and on-line news agencies. These media practice a kind of journalism based on the idea that the citizen should receive news directly from the source, avoiding gatekeepers and the frames of conventional media. Some claim this model, called "media of sources", has enhanced pluralism in political information. At the same time, the activity is considered a paternalist action of State, which appropriates journalistic techniques and procedures to influence public opinion. These are the dilemmas discussed in this article, which presents a historical synthesis of the evolution of Brazilian Legislative Branch (Senate and Chamber of Deputies) institutional media.
\end{abstract}

\section{Keywords:}

political information; public information; public journalism; political representation

\section{Introdução}

Há mais de uma década, o Parlamento brasileiro iniciou a criação de sistemas de comunicação específicos para as duas casas legislativas: a Câmara dos Deputados e o Senado Federal. Ambos os sistemas são compostos por jornal impresso, canal de TV a cabo, emissora de rádio e agência de notícias «online». A institucionalização de uma política de comunicação voltada para aproximar o Parlamento da sociedade e do cidadão é um processo recente no Brasil, cujos marcos foram a criação da «TV Assembléia» de Minas Gerais, em 1995, e da «TV Senado», em 1996, a partir do espaço aberto com a legislação da TV por assinatura (Lei 8977/95), que regulamentou o sistema de radiodifusão por assinatura no País e permitiu a criação de canais dos poderes Judiciário e Legislativo, além das emissoras universitárias e comunitárias. 
A Câmara dos Deputados já possuía, desde 1961, um serviço de radiodifusão que, a partir de 1963, ficou também responsável pela divulgação dos trabalhos legislativos no programa «Voz do Brasil», além de possuir um boletim informativo, editado desde 1971. A Câmara seguiu o caminho dos outros órgãos legislativos e entrou na comunicação eletrônica com veículos próprios na década de 1990. Além da «TV Câmara»e do serviço telefônico 0800 (ligação gratuita), criados em 1998, a instituição transformou o boletim informativo em «Jornal da Câmara»e iniciou as transmissões da «Rádio Câmara» em 1999. No ano 2000, seu último veículo entrou em funcionamento: a «Agência Câmara».

Câmara e Senado, ao institucionalizarem sistemas de jornalismo público, com rádio, TV, jornal impresso e agência «online» de notícias, baseiam-se no princípio constitucional de que o cidadão tem direito à publicidade dos atos, decisões e demais atividades legislativas. Afinal, em tese, o trabalho de toda instituição pública deve ser acessível à sociedade. A criação desses veículos baseia-se, ainda, no diagnóstico de que é dever da instituição complementar a atuação da imprensa na publicização das atividades parlamentares, buscando compensar as deficiências da mídia privada.

A desinformação do público sobre o Legislativo compromete a legitimidade da representação popular e do mandato parlamentar. Afinal, a visibilidade é da natureza do poder, como destaca Thompson (1995). Os deputados e senadores são eleitos pelo povo. Como eles podem, então, representar seus eleitores, se a população não é devidamente informada sobre suas atividades rotineiras, como pronunciamentos, projetos de leis, participação em comissões? Sem informação sobre as atividades parlamentares, como exigir que população seja vigilante e faça cobranças continuadas sobre as atividades daqueles que foram eleitos para defender seus interesses?

A crise de credibilidade das instituições políticas, especialmente dos Parlamentos, demonstra que há uma exigência maior dos cidadãos por transparência nas administrações (JARDIM, 2006) e dos próprios representantes por maior visibilidade para seu trabalho (COOK, 1989; FREITAS, 2004). A falta de informação dos cidadãos sobre as funções e o funcionamento das casas legislativas pode levá-los inclusive a questionar a validade do gasto para mantê-las (FREITAS, 2004). Em direção similar, Miguel aponta que "a recuperação dos mecanismos representativos depende de uma maior compreensão do sentido da própria representação" (MIGUEL, 2003: 123). Ao contrário, portanto, dos veículos comerciais, a motivação para tais emissoras não é econômica, mas política, ancorada na disputa entre grupos de interesses, entidades e instituições por visibilidade social.

Aliada à possibilidade tecnológica, a busca de uma solução para a crise de representatividade das instituições políticas estimulou a contratação de profissionais do jornalismo e a criação das emissoras e jornais próprios nas diferentes esferas do governo. Segundo alguns estudos recentes (FREITAS, 2004; JARDIM, 2006; RENAULT, 2004; SANTOS, 2005), a aproximação do Parlamento com a sociedade seria uma das razões primordiais para a criação dos veículos de comunicação legislativos.

Como destaca Moisés, a legitimidade das instituições tem estreita relação com a cultura política, assim como o funcionamento institucional interfere diretamente nas crenças da população em relação ao sistema político (MOISÉS, 1995: 76). Aliás, também Weber destaca que nas relações entre dominantes e dominados "a dominação costuma apoiar-se internamente em base jurídicas, nas quais se funda a sua 'legitimidade', e o abalo dessa crença na legitimidade costuma acarretar conseqüências de grande alcance" (WEBER, 1997: 128). 
A importância política dos veículos de comunicação é uma concepção presente em vários estudos. Muitas pesquisas apontam que as próprias regras políticas passam a ter um valor alterado com a crescente influência social dos meios de comunicação sobre o campo político (LIMA, 2001; MIGUEL, 2002; RUBIM, 1994). Giovanni Sartori chega a utilizar a expressão "videopolítica" para definir o novo poder político da televisão nas sociedades contemporâneas de divulgar um fato e, com essa ação, fazê-lo acontecer (SARTORI, 2001). Um tipo de "capital transferido" passa a ser importante para a legitimidade dos atores, ou seja, passam a valer na disputa política características, qualidades e o reconhecimento obtidos em outras atividades, como o campo artístico ou a própria mídia (BOURDIEU, 2006: 189-190; MIGUEL, 2001: 8).

Na mesma linha de pensamento, a publicidade em relação às ações de governo já foi devidamente defendida por Norberto Bobbio, segundo o qual "o poder político é o poder público (...) mesmo quando não é público, não age em público, esconde-se do público, não é controlado pelo público" (2005: 28). Para Bobbio, a República diferencia-se dos regimes autoritários ou absolutistas exatamente porque há um controle público do poder e a livre formação de uma opinião pública (2005: 28). O caráter público do governo representativo é ressaltado na passagem em que o autor argumenta que a assembléia é a reunião dos representantes do povo; se a decisão for pública apenas para seus representantes, e não para todo o povo, as reuniões devem ser abertas ao público de modo que qualquer cidadãos a elas possa ter acesso (BOBBIO, 2005: 30)

Dessa forma, Bobbio concorda com Carl Schmitt na idéia de que "a representação apenas pode ocorrer na esfera da publicidade" (2005: 30) e de que a democracia precisa do exercício dos direitos de liberdade e só pode funcionar quando as ações dos governantes são "esmiuçadas, julgadas e criticadas quando tornadas públicas" (2005: 30). Para cumprir a obrigatoriedade da publicidade das ações e, ao mesmo tempo, garantir uma divulgação favorável de informações, os governos desenvolveram uma série de estratégias que incluem desde a tradicional assessoria de imprensa até os novos veículos de mídia institucionais, passando por campanhas de publicidade institucional e promoção de eventos, entre outras.

O amadurecimento da democracia requer, necessariamente, liberdade de expressão - o que inclui, necessariamente, liberdade de opinião. Aliás, no Brasil, a mídia é ardorosa defensora da livre expressão de idéias; entretanto, contraditoriamente, ela priva o povo brasileiro da liberdade de opinião de seus legítimos representantes. Pode-se contra-argumentar que a mídia não é porta-voz dos parlamentares. Por outro lado, os mecanismos de divulgação de opiniões de celebridades em todas as mídias é um impressionante fenômeno de terceirização da representação popular. Ora, se essas pessoas famosas falam em nome do povo, por que, então, não permitir que seus legítimos representantes também tenham voz na mídia? Obviamente, não podemos deixar de considerar o fator de concorrência da mídia com os políticos pela representação popular, o que pode explicar em parte tal comportamento.

É notório que há vozes políticas permanentes na mídia. Entretanto, do total de 594 parlamentares (513 deputados e 81 senadores), poucos têm espaço, exceto se forem envolvidos em escândalos, gafes e vazamentos de informação. O chamado "alto clero" sempre está presente na mídia, mas o espaço é garantido por outras razões, outras formas de capital, alheias ao status de representante popular. Tanto é que existem deputados e senadores que são completamente desconhecidos pela população. Seu reconhecimento se limita ao seu estado de origem, aos seus rincões eleitorais, e não é raro que também para isso esses parlamentares controlem mídias locais.

Como já foi ressaltado, o ideal é otimizar o potencial da informação pública para a promoção da cidadania e o fortalecimento da representação política no Brasil. Portanto, os veículos de informação não se limitam à divulgação fragmentada e episódica sobre o Parlamento. A ação contempla a emissão sistemática e continuada de conteúdos sobre o mesmo tema, de modo contextualizado e detalhado, a fim de oferecer elementos para o cidadão receptor entender o processo legislativo e a conjuntura política, além do noticiário factual. Essa é a forma peculiar do Poder Legislativo de aplicar alguns dos princípios do chamado 
«jornalismo cívico» ou «jornalismo público».

\section{Jornalismo público}

O movimento americano chamado de «Civic Journalism» é uma tentativa de abandonar a noção de que jornalistas e seu público são "espectadores" do processo político e social, conforme o «Pew Center for civic journalism», uma fundação voltada para a propagação dessa modalidade de jornalismo. "No centro da noção de «civic jornalism» está a crença de que o jornalismo tem uma obrigação para com a vida pública, uma que vai além do simples relato de notícias ou a descoberta de fatos" (1).

Segundo Traquina, esse novo jornalismo surge na década de 1990 para tentar reverter a progressiva falta de credibilidade da mídia comercial ao redor do mundo, especialmente nos Estados Unidos (TRAQUINA, 2001: 171). O autor escolhe a denominação de Jornalismo Cívico pela ênfase que os adeptos da prática dão ao conceito de cidadão. Entretanto, Traquina reconhece que a prática também recebe os nomes de "jornalismo comunitário", de "serviço público", e simplesmente "público".

Umas das principais diferenças, portanto, do jornalismo público em relação ao jornalismo convencional está na definição dos critérios de noticiabilidade. A noticiabilidade - conjunto de requisitos que se exige de um fato para que se torne uma notícia, ou seja, adquira existência pública (LALÍNDE, 1990) - é um componente importante nas análises sobre o jornalismo, especialmente aquelas identificadas com a perspectiva teórica de «Newsmaking». A noticiabilidade é constituída pelos critérios, operações e instrumentos com os quais os órgãos de imprensa enfrentam a tarefa de ESCOLHER as notícias (WOLF, 1995) e está vinculada ao processo de rotinização e estandardização das práticas produtivas, conduzindo a critérios como o espaço disponível e a política editorial, a aprovação do anunciante e a apreciação do leitor (BERGER, 1996).

Para uma definição dos valores-notícia, vários autores fornecem pistas. Uma vez que não há espaço para noticiar todos os fatos do contexto social, questões culturais, ideológicas, políticas e econômicas interferem na escolha dos acontecimentos que devem virar notícia.

De fato, os valores-notícia, que os jornalistas freqüentemente sugerem ser algo de intrínseco aos acontecimentos, para serem deduzidos utilizando o 'sentido noticioso', são códigos culturalmente específicos de contar 'estórias' (BIRD-DARDENNE, 1993: 268).

Os critérios identificados por Johan Galtung e Mari Ruge em um estudo sobre o noticiário internacional freqüência, amplitude, clareza, significação, consonância, imprevisibilidade, continuidade, composição, referência a nações de elite, referência a pessoas de elite, referência a pessoas, referência a algo negativo são um exemplo dos critérios adotados no jornalismo (GALTUNG; RUGE, 1993: 71; KUNCZIK, 1997: 245246). Mauro Wolf (1995: 179), por sua vez, agrupa os diferentes valores-notícia relativos a quatro aspectos principais: conteúdo, produto, público e concorrência.

Alguns autores ressaltam o papel dos valores-notícia, ou «news judgment», na denominação precisa de Gaye Tuchman (1993: 83), como defesa do jornalista que os invoca como critérios profissionais e técnicas objetivas na hora das críticas. O aprendizado dessas regras no ambiente profissional, através da socialização do jornalista, serve como facilitador das rotinas, uma vez que a adoção desses critérios possibilita o cumprimento das tarefas dentro do prazo disponível, além de constituir um freio aos jornalistas (BREED, 1993). A noticiabilidade, portanto, é definida em conjunto pelos informadores através de um complexo processo de negociação que envolve a instituição como um todo, os profissionais e as fontes de informação (TUCHMAN, 1983: 25). A partir dessa negociação são definidas as regras e os métodos para coleta, seleção e apresentação 
das informações ou dos fatos noticiosos.

\section{Veículos diferenciados}

O Sistema de Comunicação da Câmara dos Deputados, de acordo com o Manual da Redação, tem como objetivos gerais: evitar distorções na imagem pública da instituição; permitir a participação política da sociedade no processo legislativo por meio da divulgação antecipada de informações sobre as atividades parlamentares; e garantir o tratamento respeitoso a todo cidadão que procure a instituição. Os veículos jornalísticos têm ainda mais duas "missões básicas": divulgar o trabalho legislativo que não recebe cobertura do restante da mídia; e ser fonte de informação jornalística sobre a Câmara (MALAVAZI, 2004: 23-24).

Ainda segundo o Manual, o princípio básico do trabalho nos veículos é "a informação", o que implica "a busca de isenção no trabalho profissional” (MALAVAZI, 2004: 24). Para cumprir com esses objetivos, o Manual enumera alguns princípios que devem nortear o trabalho jornalístico: interesse público, precisão, eficiência, eficácia, exatidão, ética e responsabilidade (2004: 26-29). Ainda que o Manual de Redação da Secom não diferencie a missão dos diferentes veículos de comunicação da Casa, é possível distinguir as possibilidades que cada mídia contempla.

A emissora de TV, criada na Lei do Cabo, é transmitida por sinal UHF em Brasília e para os telespectadores da TV por assinatura no resto do Brasil. A TV Câmara tem programas jornalísticos, de entrevistas, de debates e culturais, mas privilegia a transmissão ao vivo das votações do Plenário. Uma das indicações do Manual é, contudo, evitar a "burocratização e o simples registro do fato" (MALAVAZI, 2004: 33) na cobertura jornalística. A Rádio Câmara também transmite as sessões ordinárias de votação, mas preenche boa parte da grade horária com música. Todo o material produzido pela rádio é compartilhado com mais de mil emissoras comerciais de todo o País por meio da internet. Por sua vez, a Agência Câmara divulga em tempo real tudo o que ocorre na Casa, com especial destaque para as audiências públicas e seminários promovidos pelas comissões. Em geral, tais eventos são noticiados de forma resumida nos demais veículos da mídia comercial ou são simplesmente ignorados pela imprensa.

Ao Jornal da Câmara, tablóide impresso de oito páginas, cabe "conciliar, em espaço limitado, a súmula do debate parlamentar com os demais acontecimentos diários” (MALAVAZI, 2004: 121). Ou seja, o jornal precisa noticiar um resumo dos debates do Plenário e das discussões e votações das comissões. O jornal tem como diretriz, segundo o Manual, incluir o maior número possível de deputados em suas páginas, sem que isso desvirtue o caráter jornalístico da cobertura. Oficialmente, a cobertura das reuniões das comissões e audiências públicas é extraída do material produzido pela sua agência de notícias. Na prática, contudo, o jornal e a agência contam com apenas uma equipe de reportagem, que cobre os debates em plenário, as reuniões de comissões e demais eventos.

Apesar de sua tiragem e distribuição limitada (2), o jornal é aproveitado pelos parlamentares de diferentes maneiras, uma vez que, além da cópia impressa, fica disponível na internet no formato «pdf». Dessa forma, alguns deputados imprimem as páginas de seu interesse e anexam aos boletins pessoais produzidos por suas assessorias particulares, que os enviam aos eleitores. Os principais leitores da publicação, contudo, são os próprios deputados, que geralmente reclamam quando as páginas da publicação não trazem suas declarações feitas no Plenário no dia anterior.

Com alcance bastante limitado, o Jornal da Câmara pode ser usado pelos deputados para atingir diretamente a base eleitoral, uma vez que podem controlar e direcionar a distribuição do material produzido por meio de cópias das edições publicadas em arquivos digitais na página da instituição. A Rádio Câmara, por sua vez, 
apesar de ter seu alcance restrito a Brasília, pode ter suas matérias aproveitadas por quaisquer rádios do País, desde que haja o interesse local. Tal interesse, obviamente, pode também ser suscitado pela própria equipe de assessoria do deputado. Já a TV Câmara, que só chega ao público mais abastado das cidades que contam com televisão por assinatura, e a Agência Câmara, que usa da internet, teriam mais penetração junto aos eleitores dos grandes centros ou aos formadores de opinião locais.

Ao contrário da mídia privada, que seleciona os temas legislativos de acordo com critérios de noticiabilidade e valores-notícia que primam pelo inusitado, o pitoresco ou o denuncismo, os veículos de informação do Poder Legislativo são regidos por critérios jornalísticos que se baseiam em critérios de noticiabilidade e valores-notícia diferenciados. O que é notícia, segundo as diretrizes editoriais que orientam a cobertura dos veículos mantidos pelo Poder Legislativo, são os temas relacionados a matérias legislativas de caráter institucional, ou seja, que transcendem a esfera da atuação parlamentar individual e das iniciativas partidárias isoladas. Assim, enquadram-se nessa categoria as deliberações da Mesa Diretora, das comissões permanentes, os pronunciamentos de líderes, os debates em Plenário e nas comissões técnicas, além de votação de projetos de leis, seminários e audiências públicas.

Enquanto a mídia privada informa apenas o resultado de algumas votações avaliadas como de grande impacto social, os veículos institucionais transmitem informação a respeito de todo o processo de tramitação de um projeto de lei, por exemplo, desde a sua apresentação pelo parlamentar, até as alterações realizadas por meio de emendas e substitutivos em cada uma das comissões por onde a matéria passa, até a sua aprovação definitiva ou sua rejeição, seja no Plenário, seja de modo conclusivo/terminativo (quando não é necessário passar pelo Plenário).

Outro diferencial das mídias legislativas em relação aos meios privados é o aprofundamento da discussão pública sobre os temas tratados pelas comissões e pelo Plenário. A tematização, quase inexistente na cobertura realizada pela imprensa privada, é feita nos veículos mantidos pelo Poder Legislativo sob a modalidade de debates polêmicos, ou seja, que apresentam múltiplas visões e não apenas os chamados "dois lados da questão". Ao evitar a polarização e a dicotomia dos debates públicos, os veículos de comunicação do Poder Legislativo baseiam-se em outro princípio da comunicação pública e do jornalismo cívico: preocupamse em contribuir para a educação política do cidadão ao oferecer instrumentos analíticos para que ele entenda o processo político/legislativo em sua complexidade e para que possa, com isso, tornar-se um cidadão mais participativo e atuante na sociedade. Desse ponto de vista, a informação não é tratada como um produto mercadológico, mas essencialmente, como instrumento para o exercício da cidadania e para uma cultura política participativa.

Sob essa perspectiva, a tematização é incentivada pelos veículos institucionais, a fím de apresentar diferentes enquadramentos sobre o mesmo assunto. Como exemplos desse tipo de tematização, podemos destacar os conteúdos que complementam os noticiários, como os debates e as entrevistas nas emissoras de rádio e TV, além da síntese das discussões polêmicas no Plenário, divulgados pela internet e pelos veículos impressos.

Em termos gerais, os profissionais da «TV Câmara» justificam que seu trabalho é complicado pela falta de critérios políticos e editoriais coerentes com os princípios básicos da comunicação pública - apesar do esforço para essa adequação nos últimos anos. No jornalismo, especialmente, questiona-se a semelhança de formatos e critérios com aqueles adotados pela mídia comercial. Ao mesmo tempo, e contraditoriamente, questiona-se também a adoção de critérios que seriam institucionais, e não jornalísticos. Se a função das mídias legislativas é servir como canal de comunicação entre representantes e representados, um critério ligado ao processo de produção de leis amplia ou reduz o caráter democrático dessas mídias? Ele de fato possibilita o controle popular da atividade dos parlamentares ou é uma acomodação entre interesses desses e uma justificação da atuação dos profissionais dos veículos legislativos? 
A redefinição dos critérios de noticiabilidade e dos valores-notícia na cobertura dos veículos do Poder Legislativo faz parte de uma estratégia de política editorial que pretende estimular a participação do cidadão. Essa concepção baseia-se no pressuposto de que um sistema público de informação deve assegurar ao cidadão mecanismos de interatividade, a fim de romper o esquema tradicional de emissão unilateral de informações que condiciona o exercício da cidadania à recepção de informações divulgadas pela mídia.

No jornalismo público - entendido como prestação de serviços públicos de informação aos cidadãos - a captação das demandas e a identificação dos interesses dos diferentes segmentos de públicos é um dos diferenciais em relação à mídia privada. Afinal, como ressalta Pierre Libois (2002), a comunicação pública, na qual o jornalismo público fundamenta-se, não deveria confundir-se com administração pública no sentido tradicional; isso acarretaria práticas paternalistas e assistencialistas que, em sua visão, predominam nos atuais serviços de comunicação oferecidos por organismos públicos. A existência de mecanismos efetivos de interatividade com os receptores rompe esse esquema assistencialista/paternalista, pois deixa-se de apenas oferecer informação e passa-se a captar as respostas dos cidadãos.

\section{Comentários finais}

O sistema de informação do Legislativo pode contribuir para diversificar a cobertura sobre temas políticos no Brasil. Entretanto, como um sistema autodenominado público, caberia investir em ferramentas para reforçar a participação popular e o atendimento às demandas dos usuários. Para a adequação aos critérios de informação pública, haveria necessidade de reformular a política editorial dos veículos, a organização interna das rotinas produtivas e a rearticulação política e institucional nas atividades de informação pública. Também é preciso redefinir os padrões de oferta de informação aos públicos, buscando captar e atender eficientemente as suas demandas. É fundamental oferecer novos enquadramentos que sejam diferentes daqueles limitados aos estereótipos e estigmas sobre o Poder Legislativo.

Do ponto de vista teórico, uma das contribuições do modelo de jornalismo de interesse público é a alteração dos critérios de noticiabilidade e dos valores-notícia da mídia convencional, como foi abordado anteriormente. Com isso, esse novo modelo informativo, resultante do fenômeno da pluralização das mídias, tenta intervir nas formas de agendamento e tematização dos temas políticos e legislativos, rompendo a espiral do silencio construída pela mídia privada em torno dos temas concernentes à atuação do Poder Legislativo. Entretanto, as redefinições teóricas também são passíveis de críticas e ressalvas, a começar pela natureza conceitual desses serviços de informação: trata-se de jornalismo ou divulgação institucional? É um serviço de informação pública ou estatal?

No Brasil, existe uma dificuldade histórica no que diz respeito a essa distinção. Por definição, um sistema estatal de informação é privativo do Estado, com o objetivo de oferecer ao cidadão conteúdos informativos, culturais e educativos. Nesse sistema, cabe ao Estado a função exclusiva de financiar o sistema, nomear seus titulares e exercer controle sobre a programação. Já um sistema de comunicação pública, embora também seja um serviço público, deveria funcionar inteiramente independente do Estado, tanto do ponto de vista burocrático como de produção e emissão de conteúdos. Trata-se de uma modalidade de serviço de informação pública, caracterizado como não privativo do Estado, com autonomia editorial e administativa. Assim, o gerenciamento de um sistema de comunicação pública deve ser implantado de forma independente do governo, que não deve interferir na nomeação dos seus dirigentes, nem na sua programação. No Brasil, entretanto, os dois sistemas são comumente usados como sinônimos ou termos intercambiáveis. Portanto, em qualquer estudo sobre o assunto, essa confusão conceitual deve ser sanada no início da discussão.

Do ponto de vista sócio-político-cultural, questiona-se a efetividade e a isenção dos serviços de informação 
mantidos por instituições do Estado, como é o caso do sistema de comunicação do Poder Legislativo no Brasil. A inserção dos discursos das mídias oficiais, em tese, deveria atender às demandas da sociedade e contribuir para a constituição de um espaço público democrático e pluralista. Entretanto, a intervenção na esfera pública é reconhecidamente limitada. É notório ainda que esses canais de informação não conseguem competir com os veículos privados, que já se consolidaram diante da opinião pública. Os sistemas estatais, ao contrário, enfrentam resistências da sociedade, visto que são associados aos interesses dos dirigentes das instituições que mantém essas mídias institucionais.

Assim, os veículos estatais/públicos são percebidos como “oficiosos" pelos cidadãos, que, geralmente, desconfiam da proposta editorial desses canais de informação. Para muitos, esses veículos servem mais como instrumentos de propaganda do que de informação propriamente dita. Contudo, a principal barreira encontrada é o desconhecimento da população. No caso específico do Poder Legislativo, sequer existem pesquisas para identificar o grau de informação dos públicos sobre esses serviços e a sua aceitação.

\section{Bibliografia:}

ADGHIRNI, Z. L. Sistemas de Comunicação nos Três Poderes: quando o Estado se apropria do jornalismo para influenciar o espaço público. In: VIII COLÓQUIO BRASIL-FRANÇA DE CIÊNCIAS DA COMUNICAÇÃO, 2006. Echirolles, França, 2006..

ALDÉ, A. A construção da política: democracia, cidadania e meios de comunicação de massa. Rio de Janeiro: Fundação Getúlio Vargas, 2004.

BERGER, C. Campos em confronto: jornalismo e movimentos sociais. As relações entre o Movimento Sem Terra e a Zero Hora. 1996. Tese (Doutorado em Comunicação Social). São Paulo: ECA-USP, 2001. Disponível em: www.bocc.ubi.pt. Acesso em: 04 set. 2001.

BIRD, S. E.; DARDENNE, R. W. Mito, registro e 'estórias': explorando as qualidades narrativas das notícias. IN: TRAQUINA, N. (org.). Jornalismo: questões, teorias e “estórias”. Lisboa: Vega Ltda., 1993, pp. 263-277.

BOBBIO, N. Estado, governo, sociedade. Para uma teoria geral da política. 12a ed. Rio de Janeiro: Paz e Terra, 2005.

BOURDIEU, P. O poder simbólico. 9ª ed. Rio de Janeiro: Bertrand Brasil, 2006.

BRASIL. Secretaria de Comunicação Social. Manual de Redação: Agência Senado, Jornal do Senado. 2003. Disponível em: www.senado.gov.br/comunica/agencia/manual/m_agencia.pdf. Acesso em: 26 jan. 2007.

BREED, W. Controlo social na redacção. Uma análise funcional. IN: TRAQUINA, N. (org.). Jornalismo: questões, teorias e "estórias". Lisboa: Veja, 1993, pp. 152-166.

COOK, T. Making laws and making news. Media strategies in the U.S. House of Representatives. Washington: The Brookings Institution, 1989.

GALTUNG, J.; RUGE, M. H. A estrutura do noticiário estrangeiro. A apresentação das crises do Congo, Cuba e Chipre em quatro jornais estrangeiros. In: TRAQUINA, N. (Org.). Jornalismo: questões, teorias e “estórias". Lisboa: Vega, 1993, pp. 61-73. 
HABERMAS, J. Mudança estrutural da esfera pública: investigações quanto a uma categoria da sociedade burguesa. $2^{\mathrm{a}}$ ed. Rio de Janeiro: Tempo Brasileiro, 2003.

HELLER, A.; FERENC, F. A condição política pós-moderna. Rio de Janeiro: Civilização Brasileira, 1988.

KUNCZIK, M. Conceitos de jornalismo. 2a . ed. São Paulo: Edusp, 2001.

JARDIM, M. A. O mapa da mídia eletrônica legislativa na América Latina. Trabalho apresentado no $3^{\circ}$ Congresso Latino-americano de Ciência Política. Campinas (SP), setembro de 2006.

LALINDE, A. M. Elementos para comprender la noticia. Signo y pensamiento, no 17, 1990, pp. 11-27.

LIBOIS, B. La communication publique: por une philosophie politique des medias. Paris: L'Harmattan, 2002.

LIMA, V. Mídia: teoria e política. São Paulo: Fundação Perseu Abramo, 2001.

MATOS, H. Comunicação Pública, democracia e cidadania: o caso do Legislativo. Líbero. São Paulo: Fundação Cásper Líbero, Ano II, no 3-4, 1999, pp. 32-37.

MIGUEL, L. F.. Influência e resistência: em busca de um modelo complexo da relação mídia/política. Trabalho apresentado ao GT Comunicação e Política. Brasília, X Compós, 2001.

. Os meios de comunicação e a prática política. Lua Nova, no 55-56, 2002, pp.155-184.

. Representação política em 3-D. Elementos para uma teoria ampliada da representação política. Revista Brasileira de Ciências Sociais. São Paulo, v.18, no 51, 2003, pp. 123-140.

MOISÉS, J. A. Os brasileiros e a democracia. São Paulo: Ática, 1995.

PAZ, A. D. Rotinas produtivas e aproveitamento de notícias: uma análise da imprensa escrita da Câmara [Monografia - Bacharelado em Jornalismo]. Brasília: Faculdade de Comunicação, Departamento de Jornalismo, Universidade de Brasília (UnB), 2006.

RUBIM, A. C. Mídia e política: transmissão de poder. In: MATOS, Heloiza (org.) Mídia, eleições e democracia. São Paulo: Página Aberta, 1994.

RENAULT, L. Comunicação e política nos canais de comunicação do Poder Legislativo no Brasil. Belo Horizonte: Assembléia Legislativa do Estado de Minas Gerais, 2004.

SANT'ANNA, F. Mídia das Fontes: o difusor do Jornalismo Corporativo. Brasília: Casa das Musas, 2005.

SANTANA de F. L. C. A midiatização do parlamento: a TV Senado e as transformações na atividade político-parlamentar no Senado brasileiro. [Dissertação apresentada como requisito parcial à obtenção de título de Mestre em Comunicação Social, do Programa de Pós-Graduação da Faculdade de Comunicação Social da Universidade de Brasília]. Brasília: Universidade de Brasília, 2005.

SANTOS, M. de L. dos. Breve história da TV legislativa no Brasil: raízes e origens. In: XXIX Congresso Brasileiro de Ciências da Comunicação. Brasília, 2006.

SANTOS, P. C. P. A crise de representatividade do legislativo e a mídia: os princípios norteadores da 
implantação do sistema de comunicação institucional da Câmara [Trabalho apresentado ao Curso de Aperfeiçoamento em Mídia e Política - Instituto de Ciência Política, Universidade de Brasília]. Brasília: Universidade de Brasília, 2005.

SARTORI, G. Homo videns: televisão e pós-pensamento. Bauru (SP): EdUsp, 2001.

SOUSA, J. P. As notícias e seus efeitos: as teorias do jornalismo e dos efeitos sociais dos medias jornalísticos. Coimbra: Minerca Coimbra, 2000.

THOMPSON, J.B. Ideologia e cultura moderna: teoria social crítica na era dos meios de comunicação de massa. Petrópolis: Vozes, 1995.

TRAQUINA, N. O estudo do jornalismo no século XX. São Leopoldo: Unisinos, 2001.

TUCHMAN, G. La producción de la noticia: estudio sobre la construcción de la realidad. Barcelona: Gustavo Gili, 1983.

. A objectividade como ritual estratégico: uma análise das noções de objectividade dos jornalistas.

In: TRAQUINA, N. (Org.). Jornalismo: questões, teorias e “estórias”. Lisboa: Vega, 1993, pp. 74-90.

URBINATI, N. O que torna a representação democrática? Lua Nova. São Paulo, n. 67, 2006, pp. 191-228.

WEBER, M. Os três tipos puros de dominação legítima. In: COHN, G. (Org). Weber. São Paulo: Ática, 1997. Coleção Grandes Cientistas Sociais.

Sociologia da imprensa: um programa de pesquisa. Lua Nova, São Paulo, n. 55-56, 2002, pp.155-

184.

WOLF, M. Teorias da Comunicação. Lisboa: Editorial Presença, 1995.

ZEMOR, P. La Comunication Publique. Que sais-je? Paris: PUF, 1995.

\section{Notas:}

Este paper é resultado das atividades institucionais inseridas no projeto integrado de pesquisa "Ações de comunicação da Câmara dos Deputados para a promoção da democracia e participação popular". O grupo é filiado à linha de pesquisa "Cidadania e práticas democráticas de representação e participação política" do Programa de Pós-Graduação em Instituições e Processos Políticos do Legislativo do Centro de Formação, Treinamento e Aperfeiçoamento (CEFOR) da Câmara dos Deputados. E-mail do grupo: Pesquisa-Legislativa@googlegroups.com

(1) Disponível em: www.pewcenter.org

(2) O jornal diário tem uma tiragem de 10 mil exemplares, de segunda a sexta-feira, que são distribuídos por correio para Assembléias Legislativas, Câmaras de Vereadores e órgãos dos executivos e judiciários municipais e estaduais, além de outros locais de interesse (como aeroportos e bibliotecas) e leitores cadastrados.

Mini Currículo :

Antonio Teixeira de Barros - Doutor em Sociologia pela UnB. Jornalista da Câmara dos Deputados. 
Cristiane Brum Bernardes - Doutoranda em Ciência Política pelo IUPERJ. Jornalista da Câmara dos Deputados. 